\section{To DAPSA or not to DAPSA? That is not the question}

In a recent publication in the Annals of the Rheumatic Diseases, van Mens et al have provided an analysis of different criteria for assessment of remission and low disease activity (LDA) in psoriatic arthritis (PsA). ${ }^{1}$ We would like to congratulate the authors for a thoughtful and thorough analysis of various disease activity measures in PsA and for providing the readers with interesting data. As so often, interpretations of data and conclusions may be seen diversely from different angles and we take the liberty to interpreting the data differently than the authors themselves.

The authors have evaluated remission (REM) and LDA by the disease activity in psoriatic arthritis (DAPSA), clinical disease activity in psoriatic arthritis (cDAPSA), minimal disease activity (MDA), psoriatic arthritis disease activity score (PASDAS) and very low disease activity (VLDA) for residual disease activity. These scores differ on two accounts: first, MDA and VLDA are solely state measures and, therefore, do not provide information on the actual level of disease activity, while DAPSA, cDAPSA and PASDAS are continuous measures that allow following patients' disease activity through their whole disease history and define disease activity states, including remission and LDA; second, the philosophy behind DAPSA and CDAPSA on the one hand and MDA, PASDAS and VLDA on the other hand differs, since the latter scores comprise many aspects of psoriatic disease (PsoD) and thus include skin involvement, enthesitis, dactylitis and others, while the former focuses solely on the joint involvement of PsA, leaving the other variables of PsoD to being assessed by respective, widely validated separate scoring systems rather than lumping them together into one score. Interestingly, during the development of composite measures for PsoD, the authors themselves apparently disagree on how these should be constructed, since the components included differ among them, as can be seen in a recently summative presentation of these scores. ${ }^{2}$

Given that MDA, PASDAS and VLDA have in common that they comprise various aspects of PsoD, it was surprising to see that MDA and VLDA correlated better with DAPSA/cDAPSA REM and LDA than with the more closely related PASDAS-REM. Of note, while a LDA state for PASDAS has been defined, ${ }^{3}$ the authors did not show these data in relation to DAPSA and MDA. It would be important for the readers of the Journal if the authors could convey these data in their response. Of note, PASDAS was already affected with stringency issues in remission, allowing for almost $10 \%$ of the patients to have 4-7 tender joints, a situation hardly compatible with remission of arthritis. These data confirm and support the decision provided in recent recommendations to apply primarily DAPSA as a continuous and state measure of disease activity and MDA as a state measure. ${ }^{2}$

As elaborated in previous discussions, ${ }^{24}$ the difference between a holistic, multidimensional measure of disease activity, such as the PASDAS and MDA, and unidimensional measures, such as DAPSA or psoriasis area and severity index (PASI), has nothing to do with neglecting important aspects of disease. The authors imply this by stating that 'residual skin disease was highest in patients achieving DAPSA or cDAPSA remission...'. However, this is a misinterpretation of the DAPSA construct. The DAPSA is a measure for PsA and thus arthritis, not for PsoD. Since one has to use the PASI or body surface area (BSA) anyway to calculate a score like PASDAS or a pure state like MDA/VLDA, one can refrain from throwing it into a composite tool and such validated skin score separately to see if psoriasis is still active or not, irrespective of whether patients are in DAPSA remission or not. Physicians will interpret results from psoriasis and arthritis separately, in fact, they are forced to do this, as the therapeutic implications of disease activity in the two domains are clearly different. ${ }^{5}$ While we are permanently discussing how proper outcomes assessment is limited by physician time, the 'first lump, then separate'-strategy is not apt, at least in clinical practice. In trials, although trial endpoints should also be useful to clinical practice, we may care less.

Do we really? In fact, this multidimensional approach has already been proven to be unreliable in a previous analysis. In the PRESTA trial, the efficacy of $50 \mathrm{mg}$ vs $100 \mathrm{mg}$ etanercept weekly was compared in patients with PsA who also had significant psoriatic skin involvement. ${ }^{78}$ In the original trial, ${ }^{7}$ the $100 \mathrm{mg}$ dose showed better efficacy in reducing skin involvement, but not even a hint of higher efficacy in arthritis, enthesitis and dactylitis. The data on musculoskeletal disease were obtained by the traditional unidimensional measures, namely ACR response rates, dactylitis scores and enthesitis scores. However, when a multidimensional measure for PsA was used, ${ }^{8}$ there was a significant difference between the doses, which was not seen when DAPSA was employed. If regulators would have allowed such measure to be used as an outcome for PsA, the implication would have been to use $100 \mathrm{mg}$ etanercept weekly in all patients with PsA, while the difference observed was only based on different response of cutaneous involvement. Thus, the use of unidimensional scores, as done in the original PRESTA trial, saved society lots of costs and individual patients were spared from the risk of more adverse events that might have been seen at the higher dose. ${ }^{7}$ In contrast, the use of multidimensional measures that assess PsoD, not PsA, would have led to wrong conclusions. To only assume that lower proportions, like for VLDA compared with DAPSA-REM are more 'stringent' might be a semantically wrong conclusion - stringency may relate to external types of validity, such as progression of joint damage here (which was not assessed in the study, but non-progression was seen by us in DAPSA-REM). ${ }^{9}$

Finally, for rheumatologists, the main focus is arthritis and for that the DAPSA serves them well in daily practice. Indeed, in DAPSA remission all other musculoskeletal complaints are gone or almost gone, as also shown by the authors (no dactylitis in $100 \%$ and no enthesitis in $96 \%$ of patients in DAPSA REM), confirming our own results. ${ }^{10}$

Thus, in summary, the data presented showing the very low proportion of patients achieving VLDA imply that treatment for PsA would have to be adapted because of residual skin disease, which might put patients at risk and society at increased costs. In contrast, the high frequency of DAPSA remission reveals that the patients do very well for their PsA under the treatment provided by the authors and that some may be in need for additional local or systemic therapy for other components of their PsoD.

\section{Monika M Schoels, Josef S Smolen, Daniel Aletaha}

Department of Rheumatology, Medical University of Vienna, Vienna, Austria

Correspondence to Dr Monika M Schoels, Medical University of Vienna, Vienna 1090, Austria; monika.schoels@meduniwien.ac.at

Contributors All authors have equally contributed to this e-Letter.

Funding This research received no specific grant from any funding agency in the public, commercial or not-for-profit sectors.

Competing interests None declared.

Patient consent Not required.

Provenance and peer review Not commissioned; internally peer reviewed.

(c) Article author(s) (or their employer(s) unless otherwise stated in the text of the article) 2019. All rights reserved. No commercial use is permitted unless otherwise expressly granted. 


\section{Check for updates}

To cite Schoels MM, Smolen JS, Aletaha D. Ann Rheum Dis 2019:78:e61.

Received 9 April 2018

Accepted 19 April 2018

Published Online First 5 May 2018

\section{SLinked}

http://dx.doi.org/10.1136/annrheumdis-2018-213618

Ann Rheum Dis 2019;78:e61. doi:10.1136/annrheumdis-2018-213548

\section{REFERENCES}

1 van Mens LJJ, van de Sande MGH, van Kuijk AWR, et al. Ideal target for psoriatic arthritis? Comparison of remission and low disease activity states in a real-life cohort. Ann Rheum Dis 2018;77:251-7.

2 Smolen JS, Schöls M, Braun J, et al. Treating axial spondyloarthritis and peripheral spondyloarthritis, especially psoriatic arthritis, to target: 2017 update of recommendations by an international task force. Ann Rheum Dis 2018;77:3-17.
3 Helliwell PS, FitzGerald O, Fransen J. Composite disease activity and responder indices for psoriatic arthritis: a report from the GRAPPA 2013 meeting on development of cutoffs for both disease activity states and response. J Rheumatol 2014:41:1212-7.

4 Schoels MM, Aletaha D, Smolen JS. Defining remission and treatment success using the DAPSA score: response to letter by Helliwell and Coates. Ann Rheum Dis 2015;74:e67.

5 Coates LC, Kavanaugh A, Mease PJ, et al. Group for Research and Assessment of Psoriasis and Psoriatic Arthritis 2015 Treatment Recommendations for Psoriatic Arthritis. Arthritis Rheumatol 2016;68:1060-71.

6 Gossec L, Smolen JS, Ramiro S, et al. European League Against Rheumatism (EULAR) recommendations for the management of psoriatic arthritis with pharmacological therapies: 2015 update. Ann Rheum Dis 2016:75:499-510.

7 Sterry W, Ortonne JP, Kirkham B, et al. Comparison of two etanercept regimens for treatment of psoriasis and psoriatic arthritis: PRESTA randomised double blind multicentre trial. BMJ 2010;340:c147.

8 FitzGerald $\mathrm{O}$, Helliwell P, Mease P, et al. Application of composite disease activity scores in psoriatic arthritis to the PRESTA data set. Ann Rheum Dis 2012;71:358-62.

9 Aletaha D, Alasti F, Smolen JS. Disease activity states of the DAPSA, a psoriatic arthritis specific instrument, are valid against functional status and structural progression. Ann Rheum Dis 2017;76:418-21.

10 Smolen J, Aletaha D, Gladman D, et al. Outcomes associatded with achievement of various treatment targets in patients with psoriatic arthritis receiving adalimumab. Ann Rheum Dis 2017:76(Suppl 2):677. 